\title{
Implementasi Load Balancing Dengan Metode Peer Connection Classifier Pada Cabang PT. Astra Credit Companies
}

\author{
Rizky Apriansyah Hadi ${ }^{1}$, Desmulyati ${ }^{2}$ \\ 1,2 Program Studi Teknik Informatika Universitas Nusa Mandiri \\ Jl. Jatiwaringin No. 2, Cipinang Melayu, Makasar, Jakarta Timur - 13620, Indonesia

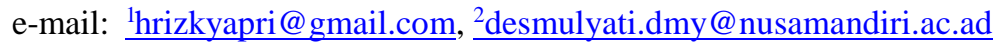

Artikel Info : Diterima : 03-06-2021 | Direvisi : 17-06-2021 | Disetujui : 30-06-2021

\begin{abstract}
Abstrak - Kebutuhan akan jaringan internet saat ini sangat penting seiring dengan perkembangan serta kemajuan komunikasi data yang semakin canggih. Dengan kegunaan seperti mencari informasi, kebutuhan mengunggah dan mengunduh dokumen dari internet, dan mengikuti video conference. Hal ini menyebabkan trafik koneksi internet menjadi meningkat, dan ini akan sangat menganggu bagi yang memiliki jaringan bandwidth yang kecil dan dapat menyebabkan terputusnya koneksi internet tersebut. Salah satu cara agar terjaga kualitas atau mutu dari konektifitas internet adalah dengan menjaga keseimbangan trafik dan penghematan bandwidth dengan membagibagi rata beban ke beberapa link atau jalur dengan menggunakan metode Per Connection Classifier (PCC) melalui teknik load balancing . Berdasarkan riset/penelitian yang telah dilakukan maka beban trafik yang diperoleh jadi lebih lancar tanpa ada penumpukan data.
\end{abstract}

Kata Kunci: Load Balancing, Metode PCC, Bandwidth

\begin{abstract}
The need for an internet network today is very important along with the development and progress of increasingly sophisticated data communications. With uses such as searching for information, the need to upload and download documents from the internet, and participate in video conferences. This causes internet connection traffic to increase, and this will be very disturbing for those who have a small bandwidth network and can cause the internet connection to be disconnected. One way to maintain the quality or quality of internet connectivity is to maintain a balance of traffic and bandwidth savings by dividing the load evenly into several links or paths using the Per Connection Classifier (PCC) method through load balancing techniques. Based on the research that has been done, the traffic load obtained becomes smoother without any accumulation of data.
\end{abstract}

Keywords: Load Balancing, PCC Method, Bandwidth

\section{PENDAHULUAN}

Saat ini kebutuhan akan internet sangat tinggi karena sudah menjadi sesuatu yang wajib dengan berbagai kegunanaan seperti mencari informasi, kebutuhan mengunggah dan mengunduh dokumen dari internet, serta mengikuti video conference. Dalam suatu institusi publik atau perkantoran penggunaan internet pada jam kerja hampir digunakan secara bersama-sama, seperti mengakses aplikasi secara online di kantor atau media informasi, web, browsing, email, chatting, video multimedia, perkuliahan daring dan sebagainya, membuat layanan internet yang tersedia akan terbebani dan saling berebut antar user satu sama lain (Utomo \& Puji Sarwono, 2020). Hal ini menyebabkan trafik koneksi internet menjadi meningkat, dan ini akan sangat menganggu bagi yang memiliki jaringan bandwidth yang kecil, dan dapat menyebabkan terputusnya koneksi internet tersebut. sehingga guna memenuhi tersebut, diharapkan ada alternatif atau solusi bagi para pemakai internet agar dapat mengakses internet tanpa ada gangguan lambat dan terputusnya koneksi internet.

Dengan kebutuhan yang tinggi akan koneksi jaringan internet di PT Astra Credit Companies (ACC) yang merupakan perusahaan yang bergerak di bidang pembiayaan mobil dan alat berat, masalah yang sering terjadi di

This work is licensed under a Creative Commons Attribution-ShareAlike 4.0 International License. 
salah satu kantor cabangnya yang terletak di Fatmawati adalah belum adanya manajemen koneksi jaringan internet, hal ini menyebabkan terjadinya overload, jaringan lambat hingga sampai terputus koneksi internetnya, memiliki kebutuhan akan koneksi jaringan internet yang tinggi seperti pengiriman email yang memiliki attachment yang cukup besar, akses pengolahan data di sistem citrix dan AOL di kantor pusat, mengikuti evaluasi dan review via aplikasi video conference seperti zoom meetings, MS Teams, Cisco Webex. Di kantor cabang Fatmawati ini memiliki 2 koneksi ISP (Internet Service Provider) yang berbeda. Untuk koneksi yang utama itu dari ISP indie home yang memiliki bandwidth 10 Mbps. Dan untuk koneksi kedua menjadi back up dari ISP icon+ yang memiliki bandwidth 5 Mbps. Implementasi load balancing diharapkan mampu memaksimalkan dari sisi ISP karena dapat menghemat biaya guna menambah koneksi jaringan internet, dan mencegah kegagalan transaksi atau transaksi terputus karena load balancing dapat meminimalisir terjadinya overload pada salah satu jalur ISP (Pangestu et al., 2018)

Terkait masalah ini, ada sebuah solusi yaitu dengan cara membuat load balancing menggunakan 2 ISP dan mikrotik sebagai routernya. Penggunaan Load balancing ini menjadi solusi yang begitu efektif karena memanfaatkan mikrotik dalam pembagian bandwidth pada jalur koneksi disetiap client yang ingin mengakses internet tanpa harus ada terjadinya ketidakseimbangan. Komputer client sebagai perantara untuk mengakses data pada komputer server (Mustafa et al., 2019). Mekanismenya adalah router mikrotik membuat tanda pada sebuah paket data dari client yang mengakses internet, dan menyetarakan beban pada kedua ISP dan memilih jalur ISP mana yang akan dilaluinya, maka diterapkanlah sebuah teknik yang dinamakan load balancing, yaitu pendistribusian suatu beban dan pengaturan jalur koneksi client terhadap sebuah service yang ada pada server dengan memanfaatkan metode distribusi koneksi menggunakan metode PCC (Per Connection Classfier). PCC (Per Connection Classfier) merupakan pengelompokan koneksi pada trafik yang masuk dan keluar lewat router lalu dibagi beban secara berimbang menghindari overload (Suryanto et al., 2018). Dan Menurut Mahmud, dengan melakukan penyeimbang beban dengan metode Per Connection Classifier (PCC) maka dapat mengatasi masalah pada ketersediaan internet dan dapat juga membagi bandwidth pada beban trafik yang dimiliki (Mahmud, 2019).

\section{METODE PENELITIAN}

Metode dalam penelitian ini adalah metode eksperimental, termasuk dalam metode kuantitatif. Metode eksperimen dapat diartikan sebagai metode penelitian yang digunakan untuk mencari pengaruh perlakuan tertentu terhadap yang lain dalam kondisi yang terkendalikan. Metode eksperimen ini meliputi studi literatur, analisa, perancangan, implementasi, pengujian sistem, evaluasi dan dokumentasi.

\section{A. Studi Literatur}

Studi literatur melibatkan berupa teori dan penelitian dari berbagai referensi. Berupa teori penelitian seperti, konsep dasar jaringan, termasuk manajemen jaringan sebagai sebuah ilmu atau teknik yamg berkaitan dengan pengelolaan dan perencanaan terhadap kinerja sebuah sistem dan komponen jaringan computer (Pratama et al., 2020), Mikrotik, metode Per Connection Classifier dan load balancing.

B. Analisa

Berikutnya pengaturan penggunaan bandwidth, akses jaringan, topologi dari jaringan, tahapan untuk menyeimbangkan beban pada kedua jalur koneksi internet di mikrotik sehingga tidak terjadi overload. Mikrotik RouterOS merupakan software (perangkat lunak) atau sistem operasi yang membuat sebuah komputer digunakan sebagai Router pada network, memiliki berbagai macam fitur untuk IP network-nya dan jaringan nirkabel/wireless (Mustofa et al., 2019). Analisa ini untuk membuat rancangan jaringan yang akan diterapkan.

C. Perancangan dan Implementasi

Software yang digunakan dalam perancangan adalah windows sebagai sistem operasi dan aplikasi winbox sebagai console untuk mengkonfigurasi router mikrotik dan implementasinya menggunakan Mikrotik Routerboard tipe 450g. Dimana Router sebagai perangkat jaringan yang memilik fungsi mengkoneksikan beberapa jaringan, baik yang sama maupun berbeda dari segi teknologinya (Sembiring \& Novendra, 2019)

D. Pengujian

Pada tahap ini penulis melakukan testing menggunakan Mikrotik Routerboard tipe R450G yang terdiri dari pengujian awal dan akhir. 


\section{HASIL DAN PEMBAHASAN}

\section{Skema Jaringan}

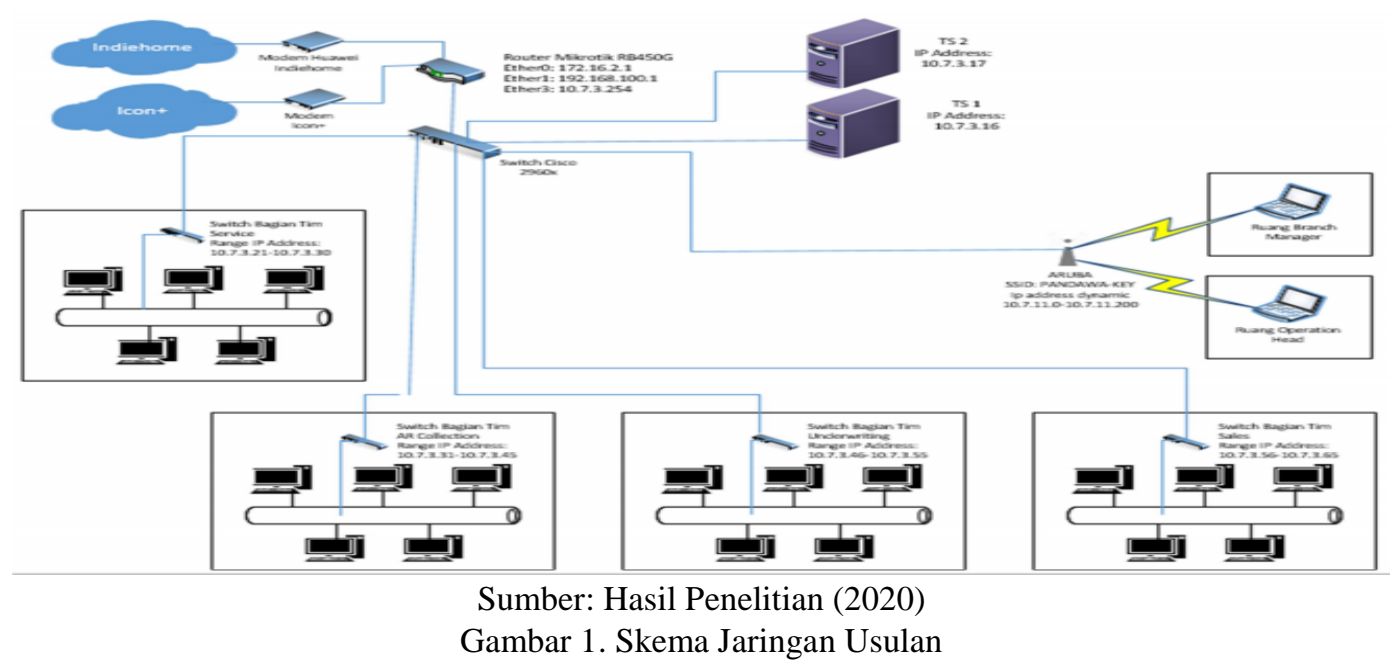

Gambar skema jaringan diatas adalah skema jaringan usulan yang penulis usulkan pada ACC Cabang Fatmawati tetap dengan menggunakan dua buah ISP yang berbeda yaitu dari Indiehome 10mbps dan Icon+ 5 mbps , menggunakan satu buah mikrotik routerboard tipe R450G agar dapat mampu menaikkan kinerja pada jaringan dan untuk masing-masing gedung tetap menggunakan switch Cisco 2960X. Jaringan komputer adalah bentuk penggabungan diantara komputer dengan komunikasi pada system komputer yang terorganisir (Robbani et al., 2020)

Berikut untuk gambar Topologi jaringan detail Load Balancing metode PCC, dimana topologi adalah suatu bentuk atau struktur jaringan yang menghubungkan komputer satu dengan yang lain:(Rianto, 2019)

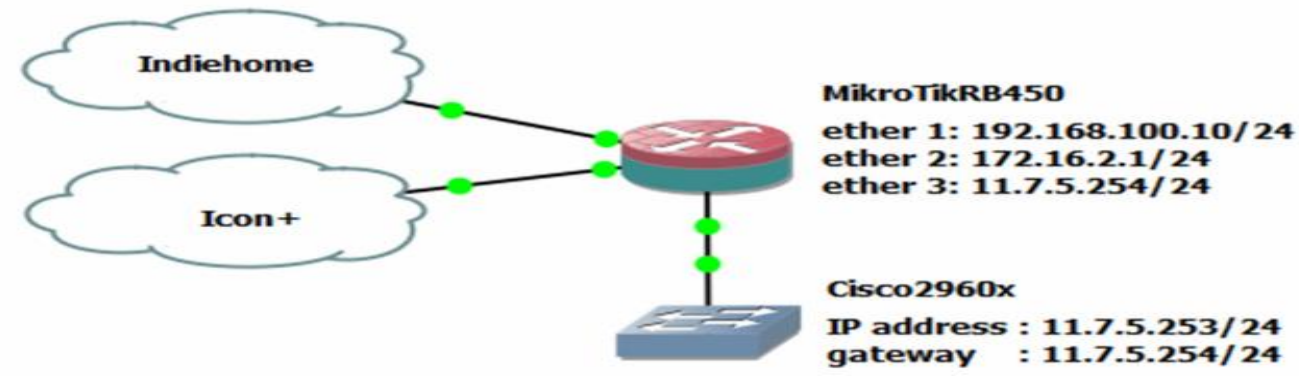

Sumber: Hasil Penelitian (2020)

Gambar 2. Gambar detail Topologi jaringan load balancing metode PCC

\section{Keamanan Jaringan}

Keamanan jaringan yang akan digunakan pada ACC Cabang Fatmawati masih menggunakan yaitu menggunakan firewall dan antivirus Trendmicro.

\section{Rancangan Aplikasi}

Dalam merancang jaringan usulan penulis menggunakan IP Publik (ether1) yang digunakan untuk menghubungkan ke ISP Indiehome, IP Publik 2 (ether2) untuk menghubungkan ke ISP Icon+, sedangkan IP lokal (ether3) digunakan untuk menghubungkan ke client. Berikut gambar daftar IP address yang terdapat pada gambar detail topologi load balancing :

Tabel 1. Tabel IP Address Router Mikrotik R450G

\begin{tabular}{llll}
\hline Perangkat & Interface & IP Address & Gateway \\
\hline \multirow{2}{*}{ Router Mikrotik } & ISP 1 (ether1) & $192.168 .100 .10 / 24$ & 192.168 .100 .1 \\
& ISP 2 (ether2) & $172.16 .2 .1 / 24$ & 172.16 .2 .254
\end{tabular}




\begin{tabular}{cccc} 
& Lokal (ether3) & $11.7 .3 .254 / 24$ & - \\
Switch 2960x & Vlan1 & $11.7 .5 .253 / 24$ & 11.7 .3 .254 \\
\hline
\end{tabular}

Sumber: Hasil Penelitian (2020)

Untuk mengimplementasi load balancing di router Mikrotik dibutuhkan konfigurasi mangle, Konfigurasi mangle berfungsi sebagai penanda paket agar diarahakan sesuai dengan rule routing yang ada. Pada load balancing dengan metode PCC ini ada tahapan konfigurasi mangle yang penulis gunakan, yaitu:

1. Chain Prerouting adalah proses dimana router dapat memanpulasi paket sebelum paket diroute-kan.

2. Chain Input adalah proses pemeriksaan paket yang akan memasuki dan diproses oleh router pada salah satu interface.

3. Chain Output adalah proses pemeriksaan paket yang telah diproses oleh router yang akan menuju keluar sebelum proses routing.

\section{Pengujian Jaringan}

Pengujian jaringan dilakukan untuk melihat adanya perbedaan antara jaringan awal dan jaringan akhir yang diusulkan penulis, adapun pengujian jaringannya sebagai berikut:

a. Pengujian Jaringan Awal

Pada pengujian jaringan awal ini, belum di terapkannya metode PCC pada Load Balancing. Berikut uji coba konektifitas berdasarkan jaringan berjalan:

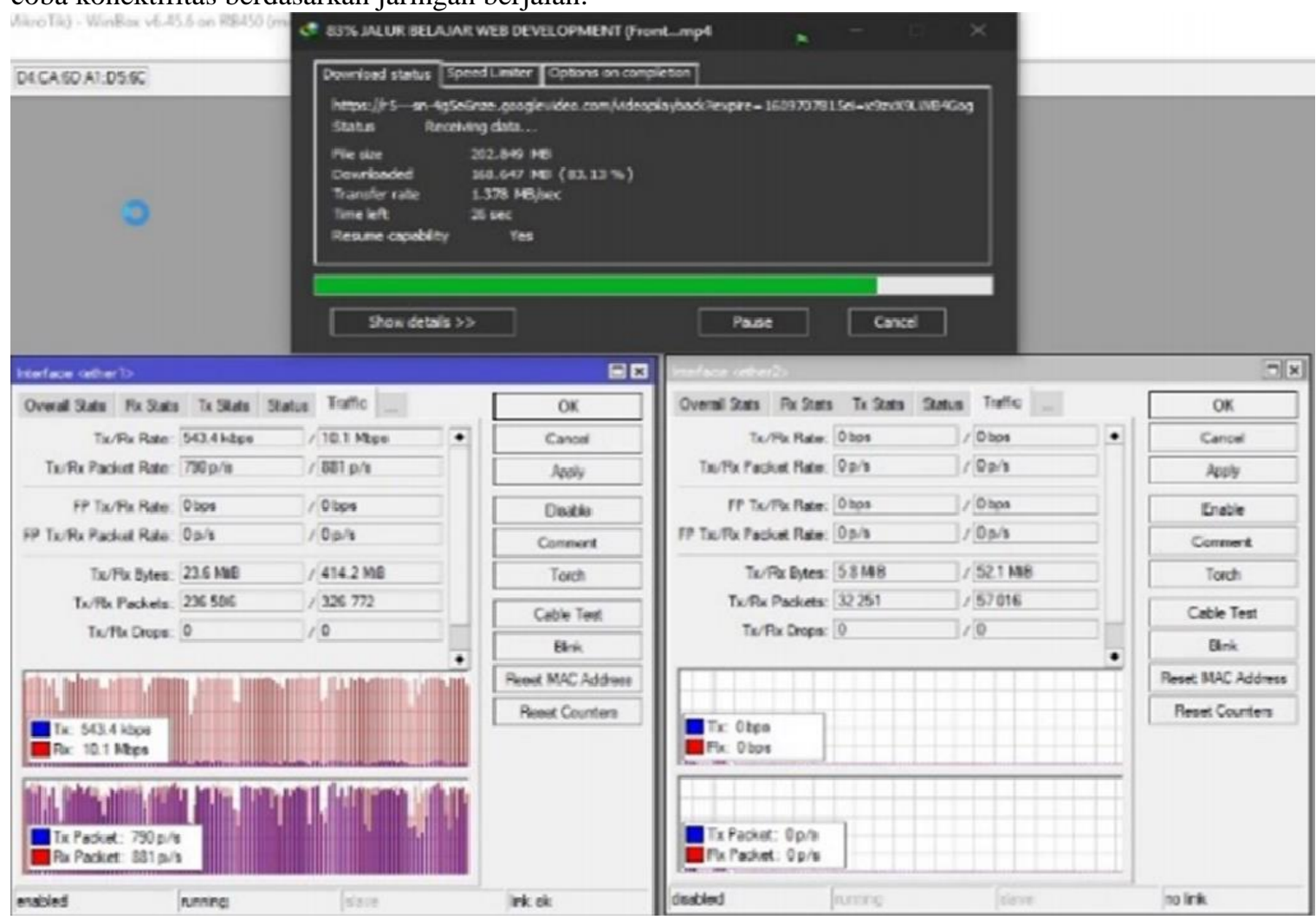

Sumber: Hasil Penelitian (2020)

Gambar 3. Koneksi Jaringan Awal Tanpa Load Balancing

Gambar diatas merupakan hasil Analisa traffic yang telah terjadi ketika koneksi jaringan sedang penuh atau sedang banyak digunakan pada ISP 1 dan ISP 2 kosong karena link tidak digunakan. Hal ini yang sering menyebabkan sering terjadi link lambat dan tidak efisien dalam penyewaan bandwidth pada ISP.

\section{b. Pengujian Jaringan Akhir}

Pengujian jaringan akhir adalah pengujian jaringan berdasarkan skema jaringan usulan yang penulis rancang untuk ACC Cabang Fatmawati, pada pengujian jaringan akhir ini sudah diterapkan load balancing dengan metode PCC. Pengujian jaringan setelah diterapkannya load balancing metode PCC stabil, penulis 
Computer Science (CO-SCIENCE)

Volume 1 No. 2 Juli 2021 | E-ISSN: 2774-9711

melakukan testing menggunakan Mikrotik Routerboard tipe R450G yang terlihat dari capture RouterOS WinBox. Berikut ini adalah pengujian jaringan akhir yang penulis usulkan:

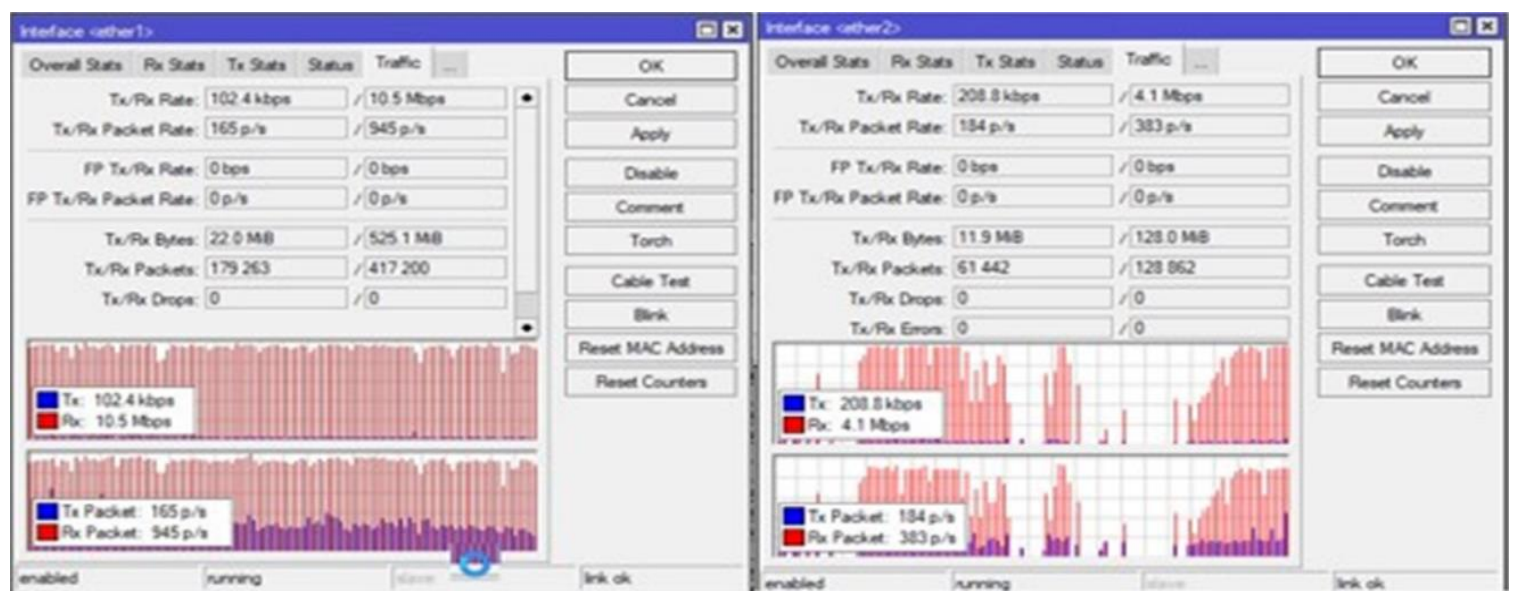

Sumber: Hasil Penelitian (2020)

Gambar 4. Tampilan Trafik jaringan dengan Load Balancing

Kesimpulannya berdasarkan dari monitoring tampak hasil dari capture traffic tersebut bahwa di masing-masing ISP saat download file dapat dilihat telah memaksimalkan bandwidth pada masing-masing ISP. Parameter yang dilihat dari kedua traffic di interface adalah besaran rata-rata distribusi (penyebaran) per gateway ISP. Pada interface ISP-1 dan interface ISP-2 terlihat packet dan bytes yang telah dilewati.

Berikut data perbandingan penyetaraan kecepatan sebelum dan sesudah menggunakan Teknik load balancing melalui monitoring dari masing masing gateway ISP dapat dilihat pada Tabel 2 dan Tabel 3:

Tabel 2. Hasil monitoring sebelum menggunakan load balancing

\begin{tabular}{|c|c|c|c|c|c|}
\hline \multirow{2}{*}{ File Size } & \multirow{2}{*}{ Kecepatan/30Sec } & \multicolumn{2}{|c|}{ ISP 1} & \multicolumn{2}{|c|}{ ISP 2} \\
\hline & & Download & Upload & Download & Upload \\
\hline \multirow{11}{*}{$220 \mathrm{Mb}$} & 1 & $10 \mathrm{Mbps}$ & $274 \mathrm{Kbps}$ & & \\
\hline & 2 & $10 \mathrm{Mbps}$ & $278 \mathrm{Kbps}$ & & \\
\hline & 3 & $10 \mathrm{Mbps}$ & $291 \mathrm{Kbps}$ & & \\
\hline & 4 & $10 \mathrm{Mbps}$ & $328 \mathrm{Kbps}$ & & \\
\hline & 5 & $10 \mathrm{Mbps}$ & $296 \mathrm{Kbps}$ & & \\
\hline & 6 & $10 \mathrm{Mbps}$ & $205 \mathrm{Kbps}$ & & \\
\hline & 7 & $10 \mathrm{Mbps}$ & $342 \mathrm{Kbps}$ & & \\
\hline & 8 & $10 \mathrm{Mbps}$ & $201 \mathrm{Kbps}$ & & \\
\hline & 9 & $10 \mathrm{Mbps}$ & 192 Kbps & & \\
\hline & 10 & $10 \mathrm{Mbps}$ & $236 \mathrm{Kbps}$ & & \\
\hline & 11 & $10 \mathrm{Mbps}$ & $250 \mathrm{Kbps}$ & & \\
\hline
\end{tabular}

Sumber: Hasil Penelitian (2020)

Pada tabel 2 terlihat kecepatan sebelum menggunakan load balancing yang memiliki rata-rata sebesar $263 \mathrm{Kbps}$ di ISP 1 untuk uploadnya.

Tabel 3. Hasil monitoring sesudah menggunakan load balancing

\begin{tabular}{cccccc}
\hline \multirow{2}{*}{ File Size } & \multirow{2}{*}{ Kecepatan/30Sec } & \multicolumn{2}{c}{ ISP 1 } & \multicolumn{2}{c}{ ISP 2} \\
\cline { 3 - 6 } & & Download & Upload & Download & Upload \\
\hline \multirow{3}{*}{$220 \mathrm{Mb}$} & 2 & $10 \mathrm{Mbps}$ & $328 \mathrm{Kbps}$ & $4,096 \mathrm{Kbps}$ & $196 \mathrm{Kbps}$ \\
& 3 & $10 \mathrm{Mbps}$ & $296 \mathrm{Kbps}$ & $3,341 \mathrm{Kbps}$ & $220 \mathrm{Kbps}$ \\
& 4 & $10 \mathrm{Mbps}$ & $205 \mathrm{Kbps}$ & $3,208 \mathrm{Kbps}$ & $279 \mathrm{Kbps}$ \\
& 5 & $10 \mathrm{Mbps}$ & $342 \mathrm{Kbps}$ & $2,086 \mathrm{Kbps}$ & $236 \mathrm{Kbps}$ \\
& 6 & $10 \mathrm{Mbps}$ & $201 \mathrm{Kbps}$ & $4,509 \mathrm{Kbps}$ & $230 \mathrm{Kbps}$ \\
& 7 & $10 \mathrm{Mbps}$ & $192 \mathrm{Kbps}$ & $4,716 \mathrm{Kbps}$ & $263 \mathrm{Kbps}$ \\
& 1 & $10 \mathrm{Mbps}$ & $236 \mathrm{Kbps}$ & $3,504 \mathrm{Kbps}$ & $186 \mathrm{Kbps}$ \\
\hline
\end{tabular}

Sumber: Hasil Penelitian (2020)

Sedangkan pada tabel 3, merupakan hasil monitoring sesudah menggunakan load balancing yang memiliki rata-rata http://jurnal.bsi.ac.id/index.php/co-science 
sebesar 3,637143 Kbps untuk hasil downloadnya, dan untuk uploadnya sebesar 257 Kbps di ISP 1 dan 230 Kbps di ISP 2.

\section{KESIMPULAN}

Dari hasil pengujian yang dilakukan, didapatkan beberapa hasil kesimpulan sebagai berikut: Router Mikrotik dapat menjalankan fungsi load balancing dengan metode PCC sesuai kebutuhan dengan baik. Penerapan load balancing dengan metode PCC dapat membagi paket sama rata pada kantor ACC Cabang Fatmawati dan dengan load balancing metode PCC dapat mengatasi masalah terputusnya pada jaringan internet. Dengan adanya infrastruktur jaringan yang menggunakan konfigurasi load balancing dan failover dengan metode PCC dan mangle, kecepatan bandwidth pada setiap komputer dapat terpenuhi dan client dapat mengakses internet lebih nyaman.

Hasil pengujian setelah diterapkannya load balancing dengan metode PCC ini dapat lebih memaksimalkan besaran bandwidth yang dimiliki dari kedua ISP, dengan melakukan konfigurasi peer connection classifier both addresses and ports dilewatkan 2 kali ke ISP 1 dan 1 kali ke ISP 2. Dengan perbandingan jumlah bandwidth dari masing masing kedua ISP tersebut yaitu 2:1. Dan koneksi yang terbentuk jalur datanya tetap akan masuk dan keluar dari ISP yang sama. Jika salah satu link jaringan internet terputus, maka seluruh beban akan dialihkan secara otomatis ke jaringan internet yang masih aktif.

\section{REFERENSI}

Mahmud. (2019). Implementasi Load Balancing Metode Per Connection Classifier (PCC) dan Failover menggunakan Mikrotik (Studi Kasus: STMIK PalComTech). Teknomatika, 09(02).

Mustafa, Hamzah, A., \& Rachmawati, Y. (2019). RANCANGAN INFRASTRUKTUR JARINGAN BACKBONE HYBRID DI TIGA KAMPUS IST AKPRIND YOGYAKARTA Jurnal JARKOM Vol . 6 No . 1 Juli 2019 EISSN : 2338-6304. 6(1), 34-41.

Mustofa, T. A., Sutanta, E., \& Triyono, J. (2019). PERANCANGAN DAN IMPLEMENTASI SISTEM MONITORING JARINGAN WI-FI MENGGUNAKAN MIKHMON ONLINE DI WISMA MUSLIM KLITREN GONDOKUSUMAN YOGYAKARTA. Jurnal JARKOM, 7(2).

Pangestu, Y., Setiyadi, D., \& Khasanah, F. N. (2018). Metode Per Connection Classifier Untuk Implementasi Load Balancing Jaringan Internet. PIKSEL : Penelitian Ilmu Komputer Sistem Embedded and Logic, 6(1), 1-8. https://doi.org/10.33558/piksel.v6i1.1389

Pratama, A., Fatmawati, D., Miranti, T. K., \& Syafira, A. O. (2020). ANALISIS DESAIN MANAJEMEN JARINGAN UPT-TIK UNIVERSITAS PEMBANGUNAN NASIONAL "VETERAN" JAWA TIMUR. SCAN - Jurnal Teknologi Informasi Dan Komunikasi, 15(1). https://doi.org/10.33005/scan.v15i1.1854

Rianto, S. (2019). SISTEM INFORMASI LAPORAN PENJUALAN KOMPUTER BERBASIS LAN. Jurnal Mahajana Informasi, Vol.4 No. 1, 2019 e-ISSN: 2527-8290 SISTEM, 4(1), 62-77. http://e-journal.sarimutiara.ac.id/index.php/7/article/view/729/617

Robbani, A. F., M. Ficky Duskarnaen, \& Hamidillah Ajie. (2020). DESAIN DAN IMPLEMENTASI JARINGAN KOMPUTER BARU UNTUK MENINGKATKAN KUALITAS KOMUNIKASI DATA PADA KAMPUS B RAWAMANGUN UNIVERSITAS NEGERI JAKARTA. PINTER : Jurnal Pendidikan Teknik Informatika Dan Komputer, 4(1), 14-18. https://doi.org/10.21009/pinter.4.1.3

Sembiring, E. H., \& Novendra. (2019). Perancangan Jaringan LAN Menggunakan Software Cisco Paket Tracer Di SMKN1 Minas. Universitas Lancang Kuning, 1-15.

Suryanto, Prasetyo, T., \& Hikmah, N. (2018). Implementasi Load Balancing Menggunakan Metode Per Connection Classifier (PCC) Dengan Failover Berbasis Mikrotik Router. Seminar Nasional Inovasi Dan Tren (SNIT), $1(1)$.

Utomo, A. D. N., \& Puji Sarwono. (2020). Load Balancing Per Connection Classifier dengan Pengukuran Quality of Service Pada Jaringan LAN Lingkup Universitas. Journal of Informatics, Information System, Software Engineering and Applications (INISTA), 2(2). https://doi.org/10.20895/inista.v2i2.123 